\title{
B8 Production of monoclonal antibodies in suspension culture of D1-4G2-4-15 hybridoma using spinner flasks system
}

\author{
Guillermo Marini $^{1}$, Marcia Arissawa ${ }^{1}$ \\ ${ }^{1}$ Bio-Manguinhos, Fiocruz, RJ
}

Introduction: Production of monoclonal antibodies involves in vivo or in vitro procedures. In vivo production presents great variability and difficulty of scaling-up, as well as ethical problems. In vitro processes are robust and achieve high cell densities, an easy scaling-up, and a better control/regulation of the process. The most widely used in vitro systems for antibody production include spinners and rollers flasks and bioreactors. Culture conditions have a significant impact on the cell growth and antibody production. In this work, D1-4G2-4-15 hybridoma, producer of monoclonal antibodies anti-flavivirus group antigen, were cultivated. Cellular viability, cell growth rate, IgG production, glucose and L-lactate concentrations have been used as investigation criteria in order to establish the optimized conditions of antibody production in spinner flasks.

Objective: Establish a suspension culture in spinner-flask of D1-4G24-15 hybridoma.

Methodology: D1-4G2-4-15 murine hybridoma was grown in suspension using both pendulum and impeller spinners in high glucose medium supplemented with fetal bovine serum and LGlutamine. Initially, the hybridoma culture was adapted to growth in suspension, maintaining the culture at low cellular concentration and changing the medium periodically to keep it in exponential growth phase. Subsequently, cell growth and IgG production kinetic of hybridoma were carried out to characterize the suspension culture in batch mode. Finally, the suspension culture was carried out in semi-continuous mode changing medium every $48 \mathrm{~h}$ to evaluate the cell culture behaviour at three different cell concentration ranges. Samples were taken in order to quantify metabolites and IgG production.

Results: The hybridoma adaptation to suspension culture was successfully implemented in both pendulum and impeller spinners, with specific growth rate of $0.038 \pm 0.004 \mathrm{~h}-1$ and $0.031 \pm 0.005 \mathrm{~h}-1$ respectively, and viability above $90 \%$. The cell growth kinetic in suspension culture presented an exponential cell growth during the first $48 \mathrm{~h}$, followed by a $24 \mathrm{~h}$ stationary phase. The maximum viable cells concentration in pendulum spinners was about $25 \%$ higher than that obtained in impeller spinners. The IgG production reached a maximum of $139 \pm 22 \mathrm{mg} / \mathrm{L}$ (day 5 and 6 - pendulum) and $123 \pm 23 \mathrm{mg} / \mathrm{L}$ (day 5 to 8 - impeller). Based on these results, 10-day culture in semi-continuous mode using pendulum spinners proceeded within the range of $0.4-2.0$ $\mathrm{x} 106 \mathrm{cel} / \mathrm{mL}$. The average specific growth rate was $0.031 \pm 0.03 \mathrm{~h}-1$. The 
$\operatorname{lgG}$ concentration ranged $17 \pm 3-88 \pm 11 \mathrm{mg} / \mathrm{L}$. Both results are in agreement with the literature data published. Higher cell concentration range culture at the same conditions was not feasible.

Conclusion: The suspension culture of D1-4G2-4-15 hybridoma in semi-continuous mode was established using spinner flasks. Maximum levels of IgG obtained were similar to those reported in the literature for this type of culture. The results are promising and will serve for future studies using serum-free media in order to optimize the production process.

Keywords: Hybridoma, Suspension Culture, IgG Production 